\title{
Listeria monocytogenes as a Cause of Spontaneous Bacterial Peritonitis
}

\author{
Elsa Araujo ${ }^{\mathrm{a}, \mathrm{b}}$, Manuel Barbosa ${ }^{\mathrm{a}}$, Joao Costelha ${ }^{\mathrm{a}}$, \\ Marta Pereira $^{\mathrm{a}}$, Joana Serodio ${ }^{\mathrm{a}}$
}

\begin{abstract}
Spontaneous bacterial peritonitis is a common and often serious complication of long standing ascites in the presence of advanced liver disease. We report a case of a 74-year-old woman with alcoholic cirrhosis admitted to our emergency department with a 1-week history of diffuse abdominal pain and increased abdominal perimeter. On physical examination, she had a significant abdominal distention and a positive fluid wave consistent with ascites. A diagnosis of spontaneous bacterial peritonitis was made and empiric therapy with ceftriaxone was started but the patient's condition worsened. Four days later Listeria monocytogenes was detected in peritoneal fluid culture and ampicillin was initiated according to in vitro sensibility test. The patient completed 14 days of treatment with clinical and laboratory improvement. Listeria is an uncommon cause of spontaneous bacterial peritonitis. Clinicians should be aware of the uncommon agents of spontaneous bacterial peritonitis, mainly when there is not a proper response to therapy.
\end{abstract}

Keywords: Alcoholic cirrhosis; Ascites; Spontaneous bacterial peritonitis; Listeria monocytogenes

\section{Introduction}

Spontaneous bacterial peritonitis (SBP) is an infection of ascitic fluid and the most common pathogens include gramnegative bacteria, usually Escherichia coli and gram-positive cocci. The guideline-recommended empiric treatment of SBP is a third-generation cephalosporin. However there has been growing concern about the efficacy of third-generation cephalosporins as empirical therapy of SBP due to resistant and unusual microorganisms.

Here we describe a case of SBP by Listeria monocy-

Manuscript submitted August 15, 2019, accepted August 26, 2019

${ }^{a}$ Internal Medicine Department, Unidade Local de Saude do Alto Minho, Ponte de Lima, Portugal

${ }^{\mathrm{b}}$ Corresponding Author: Elsa Araujo, Internal Medicine Department, Unidade Local de Saude do Alto Minho, Largo Conde de Bertiandos, Ponte de Lima 4990-041, Portugal. Email: elsa.med.int@gmail.com

doi: https://doi.org/10.14740/jmc3358 togenes, an unusual and intrinsically resistant agent to the empirically recommended group of antibiotics.

\section{Case Report}

We report a case of a 74-year-old woman with a history of chronic liver disease of alcoholic etiology with portal hypertension and esophageal varices and a history of upper digestive hemorrhage 5 years ago. Her regular medication included alprazolam and omeprazole. She was brought to the emergency department with a 1-week history of diffuse abdominal pain and increased abdominal perimeter, without any other symptoms. On physical examination, she had a body temperature of $37.8^{\circ} \mathrm{C}$ and no remarkable changes in blood pressure, heart rate, respiratory rate and peripheral saturation. She had a significant abdominal distention and a positive fluid wave consistent with ascites. Blood analysis revealed hemoglobin of $12.8 \mathrm{~g} / \mathrm{dL}$, platelets of $371,000 / \mu \mathrm{L}$, elevation of inflammatory markers: leukocytes of 16,090/ $\mu \mathrm{L}$ and C-reactive protein (CRP) of $21.74 \mathrm{mg} / \mathrm{dL}$, hypoalbuminemia of $2.8 \mathrm{~g} / \mathrm{dL}$ and international normalized ratio (INR) of 1.52. Abdominal ultrasound revealed large volume ascites and a subsequent diagnostic and therapeutic paracentesis was performed in which the peritoneal fluid cell count showed 3,136 leukocytes $/ \mathrm{mm}^{3}$ with $86 \%$ neutrophils consistent with the diagnosis of SBP. The patient was hospitalized with the diagnosis of SBP and medicated with ceftriaxone $2 \mathrm{~g}$ /day. Despite initial clinical improvement, on the second day of antibiotics, the patient still presented fever and elevated inflammatory markers: leukocytes $14,940 / \mu \mathrm{L}$ and CRP 17.92 $\mathrm{mg} / \mathrm{dL}$. An abdominal computed tomography was performed to exclude secondary peritonitis. On the third day of hospitalization, new paracentesis was performed and showed an increase in the number of cells with 6,783 leukocytes $/ \mathrm{mm}^{3}$ with $97 \%$ of neutrophils and on the next day the cultural peritoneal fluid of the first paracentesis revealed the presence of Listeria monocytogenes. The blood cultures were negative. Antibiotic therapy was changed according to in vitro sensibility test for ampicillin $2 \mathrm{~g}$ of $6 / 6 \mathrm{~h}$ and she completed 14 days of therapy. The patient presented clinical and laboratory improvement. After $48 \mathrm{~h}$ of targeted therapy, paracentesis showed a decrease in the number of cells with 3,753 leukocytes $/ \mathrm{mm}^{3}$ with $98 \%$ of neutrophils and on the ninth day of therapy the peritoneal fluid no longer presented criteria of $\mathrm{SBP}$ and cultural negative. 


\section{Discussion}

SBP, an infection of ascitic fluid with no evidence of an intraabdominal source [1], is a frequent complication of end-stage liver disease and it is associated with significant morbidity and mortality [2].

The diagnosis of SBP is based on neutrophil count in ascitic fluid of $>250 / \mathrm{mm}^{3}$. Ascitic fluid culture is frequently negative and is not necessary for the diagnosis of SBP, but it is important to guide antibiotic therapy. When culture is positive ( $40 \%$ of cases), the most common pathogens include gramnegative bacteria, usually Escherichia coli and gram-positive cocci (mainly Streptococcus species and Enterococci), which are responsible for more than $95 \%$ of the cases [3]. In a minority of cases $(<5 \%)$, Candida species, anaerobes, and Listeria are implicated [2].

Listeria is a gram-positive facultative anaerobic rod and its major human pathogen is Listeria monocytogenes [4]. Listeria is found in numerous sources including water, sewage, live animals, and dairy products. Transmission occurs fecalorally from contaminated food or animal products [5]. It is also found in the fecal flora of many mammals, including $5 \%$ of asymptomatic healthy adults [6].

It has been increasingly recognized as a pathogen in immunocompromised patients, particularly in infect newborns, pregnant women and the elderly [4], with an estimated annual incidence of 0.2 cases per 100,000 population in Europe and USA [7].

Cirrhosis is usually known as the most common form of acquired immunodeficiency. The cirrhotic patient has low complement and opsonin levels, dysfunctional reticuloendothelial system, neutrophil dysfunction, and a gut mucosa unusually permeable to bacteria. The permeability of the intestinal mucosa may actually be higher in alcoholic patients [6].

Alcohol consumption [8] and proton pump inhibitors are known risk factors for listeriosis [2]. Increased intracellular iron stores are thought to be important to foster the growth of Listeria [4]. Cirrhosis and hematologic malignancies are also risk factors for listeriosis, and a high index of suspicion for listeriosis must be maintained in these patients [5].

Listeria monocytogenes infection can present with a wide range of manifestations such as gastroenteritis, meningoencephalitis and septic arthritis. SBP by Listeria is a rare entity and it is usually associated with bacteriemia [8]. The first case was described in 1977 by Rheingold et al.

Listeria should be suspected as a cause of SBP when the patients have iron overload, exposure to farm animals, or poor response to empiric therapy within $48-72 \mathrm{~h}$, especially in the presence of known risk factors [6, 7]. The diagnosis of Listeria SBP is dependent on the growth of the organism in the peritoneal fluid, which normally takes 4 days.

Failure of antibiotic therapy should be suspected if there is worsening of clinical signs and symptoms and/or no marked reduction or increase in ascitic fluid neutrophil count after $48 \mathrm{~h}$ of treatment compared to levels at diagnosis.

The guideline-recommended empiric treatment of SBP is a third-generation cephalosporin, which has activity against the most common causative pathogens. Cefotaxime, a third- generation cephalosporin, has been extensively investigated in patients with SBP because it covers most causative organisms and because of its high ascitic fluid concentrations during therapy [3], but Listeria is intrinsically resistant [4]. Penicillin and ampicillin are effective against Listeria and appropriate treatment with a length of 10 - 14 days.

Consequently, patients with SBP due to Listeria do not have a satisfactory response to empiric antibiotic therapy and it is crucial to identify Listeria as the causative agent. Nevertheless, Listeria monocytogenes peritonitis was associated with a mortality rate as high as $30.7 \%$ [9], even when the antibiotic therapy was changed to ampicillin. It was not clear whether the cause of the high mortality rate was due to delayed diagnosis, inappropriate use of antibiotics, or the underlying co-morbidities of the patient population [8].

There has been growing concern about the efficacy of third-generation cephalosporins for empiric treatment of SBP because of resistant or unusual organisms causing peritonitis. Two recent studies examining the efficacy of ceftriaxone reported respective failure rates of $41 \%$ and $43 \%$ in SBP cases due to acquired bacterial resistance and insufficient susceptibility of isolated organisms $[10,11]$.

A heightened awareness of Listeria monocytogenes as a potential cause of SBP is necessary to allow for early intervention with appropriate antimicrobial therapy, given its specific treatment and distinct from what is currently used empirically. Given its increased recognition and high mortality rate, a change in empiric SBP treatment may be needed from the standard recommended third-generation cephalosporins to a combination of aminopenicillins with a $\beta$-lactamase inhibitor, particularly in areas with a higher geographical predilection for listeriosis and perhaps in patients with alcohol-related cirrhosis or when others risk factors for listeriosis are presented.

\section{Acknowledgments}

None to declare.

\section{Financial Disclosure}

None to declare.

\section{Conflict of Interest}

The authors have no conflict of interest to declare.

\section{Informed Consent}

Informed consent was obtained from the patient.

\section{Author Contributions}

EA is the physician who worked with patient and contributed to 
manuscript design and writing; $\mathrm{MB}$ and JC are the physicians who worked with patient and were involved in manuscript review; MP and JS contributed to data collection and manuscript review.

\section{References}

1. Torres MF, Lopez IA, Bueno PR, Martinez MG, Puig CRA, Lozano JR, et al. Peritonitis bacteriana espontanea por Listeria monocytogenes: presentacion de ocho casos (1992-2017) y revision de la literatura. Rev Esp Quimioter. 2018;31(6):532-536.

2. How J, Azar MM, Meyer JP. Are Nectarines to Blame? A case report and literature review of spontaneous bacterial peritonitis due to listeria monocytogenes. Conn Med. 2015;79(1):31-36.

3. European Association for the Study of the Liver. EASL clinical practice guidelines on the management of ascites, spontaneous bacterial peritonitis, and hepatorenal syndrome in cirrhosis. J Hepatol. 2010;53(3):397-417.

4. Gaspar R, Rodrigues S, Macedo G. Spontaneous bacterial peritonitis due to Listeria monocytogenes: Always to be remembered. Clinics and Research in Hepatology and Gastroenterology. 2017;41:68-70.

5. Yecies T, Inagami S. Spontaneous bacterial peritonitis caused by listeria monocytogenes associated with ascitic fluid lymphocytosis: a case report and review of current empiric therapy. Case Reports Hepatol. 2013;2013:832457.

6. Brann OS. Infectious complications of cirrhosis. Curr Gastroenterol Rep. 2001;3(4):285-292.

7. Cardoso C, Cremers I, Oliveira AP. Spontaneous bacterial peritonitis caused by Listeria monocytogenes: a case report and literature review. Ann Hepatol. 2012;11(6):955957.

8. Frachtman S, Lu L, Lau M, Greenberg S. spontaneous bacterial peritonitis due to listeria monocytogenes. A case report and a review of listeria monocytogenes peritonitis. Infect Dis Clin Pract. 2009;17:63-65.

9. Nolla-Salas J, Almela M, Gasser I, Latorre C, Salvado M, Coll P. Spontaneous Listeria monocytogenes peritonitis: a population-based study of 13 cases collected in Spain. Am J Gastroenterol. 2002;97(6):1507-1511.

10. Angeloni S, Leboffe C, Parente A, Venditti M, Giordano A, Merli M, Riggio O. Efficacy of current guidelines for the treatment of spontaneous bacterial peritonitis in the clinical practice. World J Gastroenterol. 2008;14(17):27572762.

11. Novovic S, Semb S, Olsen H, Moser C, Knudsen JD, Homann C. First-line treatment with cephalosporins in spontaneous bacterial peritonitis provides poor antibiotic coverage. Scand J Gastroenterol. 2012;47(2):212-216. 